Thorax (1964), 19, 121

\title{
Tumour-simulating intrathoracic marrow heterotopia in thalassaemia major
}

\author{
C. PAPAVASILIOU ANDP. SFIKAKIS \\ From the Department of Clinical Therapeutics, Alexandra Hospital, University of Athens
}

Haemopoiesis under certain circumstances can be supplemented by extramedullary foci of heterotopic bone marrow located in other tissues. In addition to the normal phenomenon of extramedullary haemopoiesis in newborn babies and infants, such a process has been observed, as a compensatory phenomenon, in conditions associated with abnormal function of haemopoietic tissue, such as pernicious anaemia, macrocytic anaemia of hepatic origin, osteosclerosis, extensive neoplastic infiltration of the bones (leukaemia, lymphoma, etc.), erythraemia, erythroblastosis, acholuric jaundice, and thalassaemia.

Heterotopic marrow has been described in the liver, spleen, kidneys, lymph nodes, and other tissues, and it is usually seen in a microscopically nodular form. However, rarely the extramedullary marrow takes the form of a macroscopic tumour-like mass found in the pelvis, the retroperitoneal region of the abdomen, the skull, and the thorax.

When located in the thorax, extramedullary haemopoiesis presents a radiological picture that we believe is typical.

This observation is based on the radiographs of three patients who had thalassaemia and who were seen in our hospital ; and two reported cases in the literature (Ask-Ummark, 1945; Knoblich, 1960). The radiological findings correlate well with the pathological records of other cases in which the process was disclosed at necropsy (Plonskier, 1930 ; Dawson, 1931 ; Hartfall and Stewart, 1933 ; Covey, 1935). One of our cases has been described elsewhere (Malamos, Papavasiliou, and Avramidis, 1962).

\section{CASE REPORTS}

CASE 1 B. C., a man aged 24 , was admitted to our department suffering from recurrent ulcers of both ankles. A diagnosis of Cooley's anaemia had been made at the age of 12 .

On examination the patient was pale, had a muddy yellow skin, and appeared younger than his age. He had mongoloid facies with prominent cheek bones, flat frontal bones, and a hard arched palate. The liver was slightly enlarged. There was general enlargement of the lymph nodes, particularly in the axillae. Chronic ulcers were present in the region of the ankles. The haemoglobin was 8.7 g. $/ 100 \mathrm{ml}$., haematocrit $27 \%$, R.B.C. $3,520,000$ with anisocytosis, poikilocytosis, microcytosis, target cells, hypochromia, and anisochromia. There were 7,150 white cells per c.mm. with $60 \%$ polymorphs, $36 \%$ lymphocytes, $3 \%$ eosinophils, and $1 \%$ monocytes. There were 9 erythroblasts per 100 white cells in the peripheral blood. The serum bilirubin was $0.9 \mathrm{mg} . / 100 \mathrm{ml}$. direct and $0.48 \mathrm{mg} . / 100 \mathrm{ml}$. indirect. The bone marrow showed marked hyperplasia of the red cell series, the white cell series, and of the megakaryocytes. There was no anomaly in the maturation of the red cells. The serum albumin electrophoresis pattern presented a moderate increase in the gamma globulin. The haemoglobin electrophoresis pattern revealed $90 \%$ haemoglobin ' $F$ '. The sickle-cell preparation test was negative. Studies with radioactive ${ }^{51} \mathrm{Cr}$ revealed that the life span of the red cells was 17 days for ${ }^{51} \mathrm{Cr}$ T 1/2 (normal range 27 to 36 days) and the surface counting 2,429 counts $/ \mathrm{min}$. over the spleen and 2,701 counts/min. over the liver, with a ratio of 0.89 (normal ratio $1 \cdot 0$ ). The red cell radioactive ${ }^{59} \mathrm{Fe}$ uptake was $18 \%$ in 10 days (normal range 85 to $100 \%$ ). The iron plasma clearance was 20 minutes for ${ }^{59} \mathrm{Fe} \mathrm{T} 1 / 2$ (normal range 60 to 120 minutes). The surface counting revealed no increase in the radioactivity over the liver or spleen, but a high degree of ineffective haemopoiesis of the bone marrow. The findings indicated Cooley's anaemia. A radiological bone survey showed - changes compatible with thalassaemia. A radiograph of the chest showed soft, well-defined lobulated masses measuring from 2 to $6 \mathrm{~cm}$. in diameter lying posteriorly in the paravertebral gutter from D2 to D10 (Fig. 1). The possibility of intrathoracic extramedullary haemopoiesis was considered, and a needle aspiration of the masses through the right fifth intercostal space paravertebrally, under fluoroscopic control, revealed elements usually found in the bone marrow (Fig. 2). The material obtained was rich in cell elements and precursors of red cell series and granulocytic white cells. Occasional plasma cells and reticulocytes were present. The red cells were more numerous than the white cells ( 220 red cells per 100 white cells) with a significant percentage of pro- 


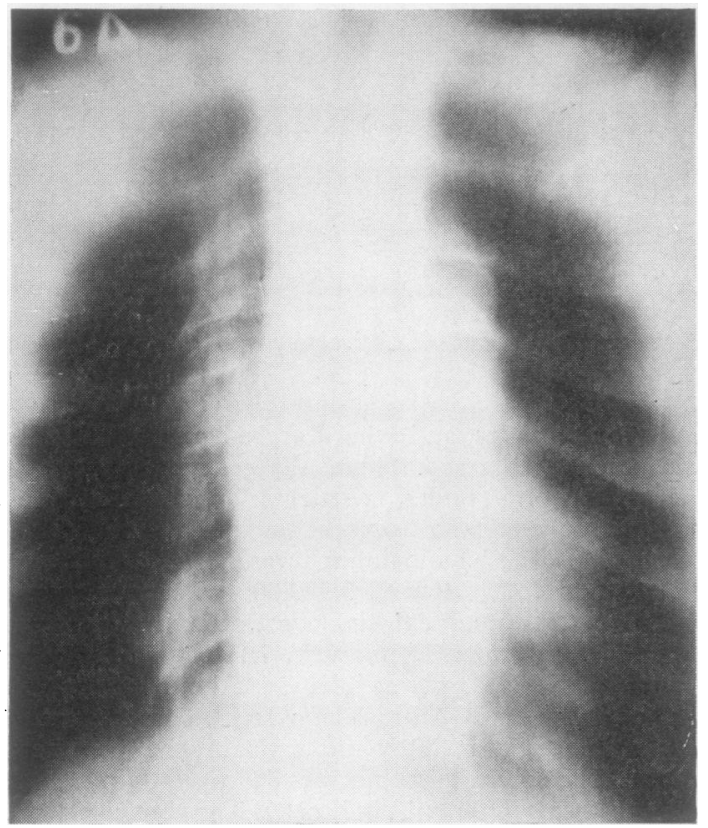

FIG. 1. Case 1. Tomogram of the chest revealing bilateral paraspinal masses presenting a segmental arrangement.

erythroblasts and basophilic erythroblasts $(9 \%$ and $39 \%$ respectively) and no megakaryocytes. Satisfactory healing of the tibial ulcers and some improvement in the haematological appearances occurred during the patient's stay in hospital.

CASE 2 B. F., a man aged 21, entered hospital because of marked anaemia that had been diagnosed at the age of 6 as Cooley's anaemia. Physical examination revealed a mongoloid face and swelling of the abdomen due to splenomegaly and, to a lesser degree, haematomegaly. Ulcerations of the skin of the feef were present. Haematological studies showed change? compatible with haemolytic anaemia: haemoglobin. 8.5 g. $/ 100 \mathrm{ml}$; haematocrit $28 \%$; R.B.C. $3,520,00 \bar{Q}$. with anisocytosis, poikilocytosis, microcytosis, hypo chromia, target cells, and basophilia; white bloof cells 43,000 per c.mm. with $69 \%$ polymorphs, $19 \%$ lymphocytes, $10 \%$ monocytes, and $2 \%$ eosinophils $\overrightarrow{-}$ The serum iron was $121.5 \gamma / 100 \mathrm{ml}$. and blood bilirubin $1.3 \mathrm{mg} . / 100 \mathrm{ml}$. The haemoglobin electro $\vec{\omega}$ phoresis pattern showed a large amount of haemo globin ' $F$ '.

The bone marrow showed marked hyperplasia especially of the red cell series. The radioactive ${ }^{31} \mathrm{Cf}$ test revealed a red cell life span of 14 days ( ${ }^{52}$ T 1/2). The iron clearance was 17 minutes for "Fev $\mathrm{T} 1 / 2$. The red cell radioactive ${ }^{59} \mathrm{Fe}$ uptake was $13.5 \%$ in 10 days. The relative surface counting rate over the sacral bone revealed ineffective haemopoiesis.Radiographic examination of the bones showed changes compatible with Cooley's anaemia. A ches $\overline{5}$ radiograph of this patient showed small masses in the right paraspinal area measuring 1-2 cm. (Fig. 3). Durê ing his stay in hospital the patient was given blood transfusions and other supportive therapy and he was discharged with orders to come back for a follow-up examination.

CASE 3 P. L., a man aged 28, entered hospital foळ̆ an annual check-up of Cooley's anaemia. Haemato $\mathbb{Q}$ logical studies revealed a microcytic hypochromic anaemia with marked morphological alterations of the peripheral red cells ; haemoglobin $7.4 \mathrm{~g} . / 100 \mathrm{ml}$. ? haematocrit $23 \%$; R.B.C. $2,990,000$ with anisocytosis poikilocytosis, microcytosis, and macrocytosis 3,500 white cells per c.mm. with $52 \%$ polymorphs $44 \%$ lymphocytes, $3 \%$ monocytes, and $2 \%$ eosino은 phils. The serum iron was $117 \gamma / 100 \mathrm{ml}$. and the serum bilirubin $1.75 \mathrm{mg} . / 100 \mathrm{ml}$. A bone-marrovi puncture showed increased hyperplasia of all celp. series. The radioactive ${ }^{51} \mathrm{Cr}$ test revealed a red celB
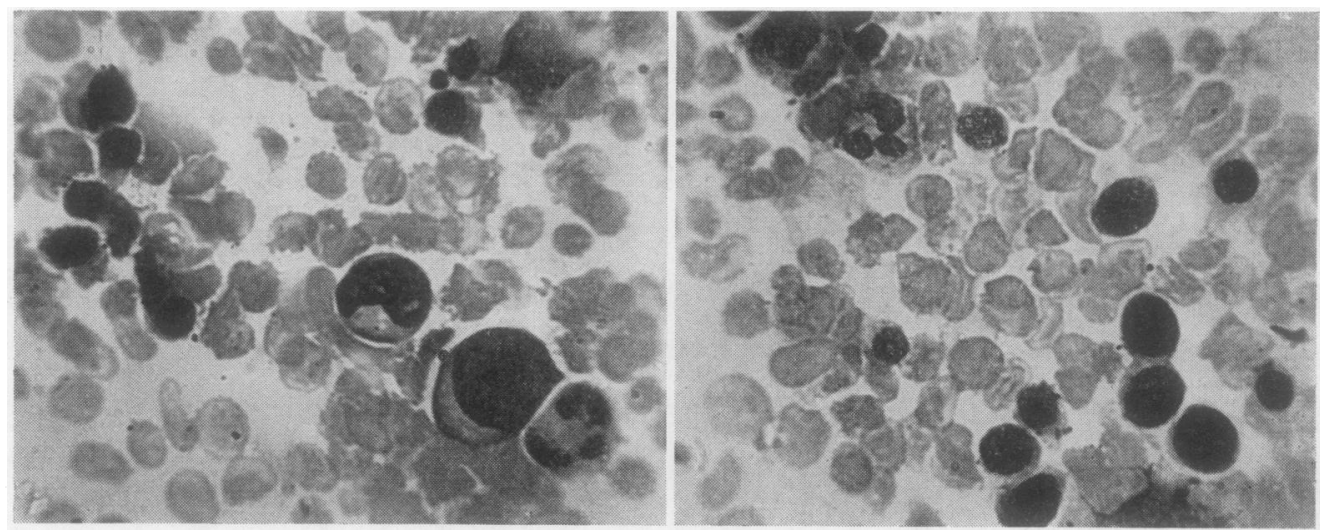

FIG. 2. Case 1. Photomicrograph of the material obtained by needle aspiration of the intrathoracic masses, revealing erythroblasts and leucocytes of differert maturation. 


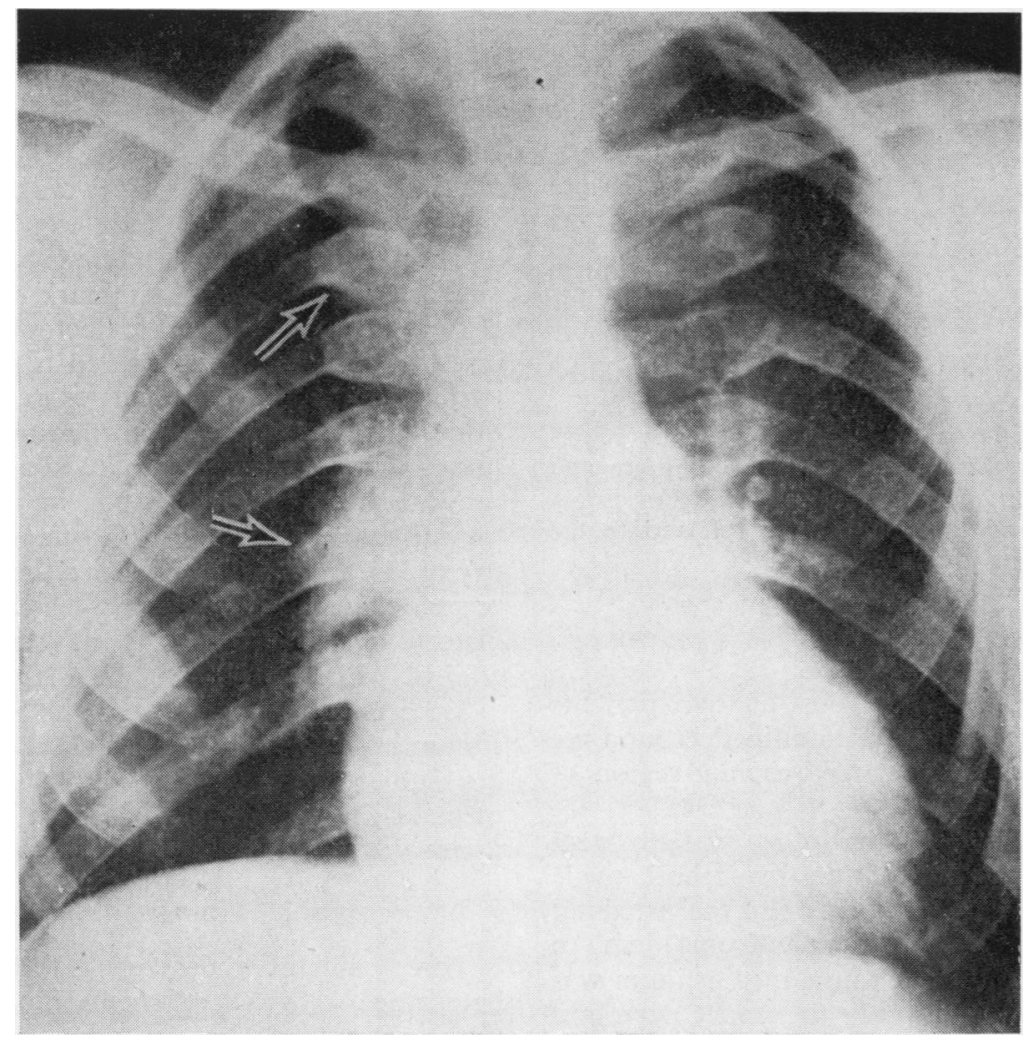

FIG. 3. Case 2. Small masses (arrows) in the right upper paraspinal area.

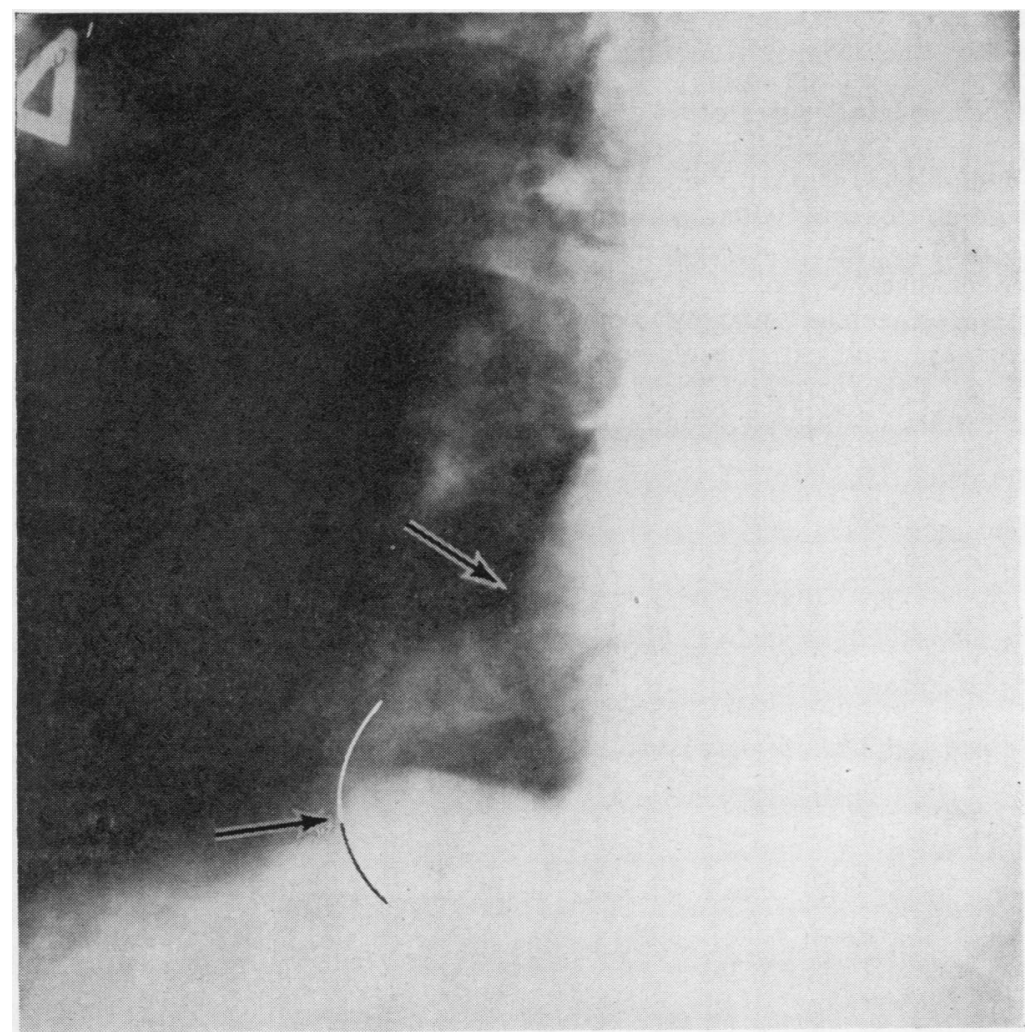

FIG. 4. Case 3. Two masses (arrows) superimposed paraspinally above the right leaf of the diaphragm. 
life span of 21 days $\left({ }^{51} \mathrm{Cr} \mathrm{T} 1 / 2\right)$. The iron clearance was 20 minutes for ${ }^{59} \mathrm{Fe} \mathrm{T} 1 / 2$. The red cell radioactive ${ }^{50} \mathrm{Fe}$ uptake was $19 \%$ in 10 days. The surface counting rate over the sacral bone marrow revealed ineffective erythropoiesis as it is usually seen in Cooley's anaemia.

Radiological examination of the bones showed changes typical of Cooley's anaemia. A chest radiograph showed two large ovoid masses partially superimposed on the right side above the diaphragm and possibly a third on the left (Fig. 4). A splenectomy was anticipated and the patient was referred to the surgical department.

\section{DISCUSSION}

The plain chest radiographs of our patients revealed multiple, soft, well-outlined, round or oval shadows located in the paraspinal region of the mediastinum.

Tomography showed that the masses were located posteriorly in the costovertebral angle adjacent to the vertebral bodies and the proximal part of the ribs. The size ranged from $1 \mathrm{~cm}$. to $6 \mathrm{~cm}$. In the first case the whole mediastinum was occupied, in the second only the upper part, and in the third case the masses were located in the lower part just above the diaphragm. In the two last cases the masses were located on the right side, whereas in the first the process was bilateral, although more prominent on the right.

The superimposition of the masses often gives a lobulated appearance to the whole process, but sometimes a segmental arrangement is present.

The patients were all anaemic young adult men suffering from Cooley's disease. Radiographs of the bones showed changes typical of a marked degree of Cooley's anaemia, namely coarse trabeculation, expansion, and extreme demineralization. Flattening of the vertebral bodies was also present. The results of isotopic studies with radioactive ${ }^{51} \mathrm{Cr}$ and ${ }^{59} \mathrm{Fe}$ were consistent witho the blood disease.

The chest radiological findings of our cases were similar to those of Ask-Ummark and Knoblich.

A review of the cases of ectopic haemopoiesis disclosed at necropsy revealed a similar location and arrangement of the masses and good correla- $\overrightarrow{0}$ tion with the radiological findings. Heterotopic $\overrightarrow{\vec{C}}$ marrow in the thorax follows a constant anatomical pattern which results in a similar radio logical appearance. This picture should be kept. in mind, and, when present, the possibility of $\overrightarrow{0}$ ectopic haemopoiesis should be considered. The history of anaemia, the bone changes, and the $\vec{v}$ clinical picture establish the diagnosis.

Since masses of this sort in the posterior mediastinum are frequently neoplastic and these patients $\overrightarrow{-}$ are subjected to surgical exploration, establishment of the correct diagnosis is important as un- $\frac{\widehat{T}}{\supset}$ necessary operations can then be avoided.

\section{SUMMARY}

Three cases of thalassaemia with bone marrowe heterotopia in the mediastinum simulating tumour masses are presented. The radiographico findings in the chest are discussed.

\section{REFERENCES}

Ask-Ummark, E. (1945). Tumoursimulating intrathoracic heterotopiß

of bone marrow. Acta Radiol., 26, 425 .
Covey, G. W. (1935). Erythroblastosis; report of case presenting a erythroblastic tumor in the thoracic cavity. Amer. J. Path., 1 to 551 .

Dawson, B. E. (1931). The Hume lectures on haemolytic icterus Brit. med. J., 1, 963.

Hartfall, S. J., and Stewart, M. J. (1933). Massive paravertebraf heterotopia of bone-marrow in a case of acholuric jaundice J. Path. Bact., 37, 455.

Knoblich, R. (1960). Extramedullary hematopoiesis presenting aহ intrathoracic tumors. Report of a case in a patient with thalas semia minor. Cancer (Philad.), 13, 462.

Semia minor. Cancer (Philad.), 13, 462 .
Malamos, B., Rapavasiliou, C., and Avramidis, A. (1962). Tumouro simulating intrathoracic extramedullary hemopoiesis. Report of a case. Acta Radiol (Stockh.), 57, 227.

Plonskier, M. (1930). Uber tumorförmige (extramedulläre, heterotoped subpleurale Knochenmarksherde. Virchows Arch. path. Anat $\mathbf{2 7 7}, 804$. 